\title{
Evaluation of a Minimum Liquid Discharge (MLD) Desalination Approach for Management of Unconventional Oil and Gas Produced Waters with a Focus on Waste Minimization
}

\author{
Ganesh L. Ghurye
}

Citation: Ghurye, G.L. Evaluation of a Minimum Liquid Discharge (MLD) Desalination Approach for

Management of Unconventional Oil and Gas Produced Waters with a Focus on Waste Minimization. Water 2021, 13, 2912. https://doi.org/ 10.3390/w13202912

Academic Editor: Pei Xu

Received: 12 August 2021

Accepted: 13 October 2021

Published: 16 October 2021

Publisher's Note: MDPI stays neutral with regard to jurisdictional claims in published maps and institutional affiliations.

Copyright: (C) 2021 by the author. Licensee MDPI, Basel, Switzerland. This article is an open access article distributed under the terms and conditions of the Creative Commons Attribution (CC BY) license (https:// creativecommons.org/licenses/by/ $4.0 /)$.
ExxonMobil Upstream Research Company, 22777 Springwoods Village Parkway, Spring, TX 77389, USA; ganesh.l.ghurye@exxonmobil.com; Tel.: +1-832-624-9363

\begin{abstract}
The objective of this research study was to evaluate the feasibility of using a minimum liquid discharge (MLD) desalination approach as an alternate management option for unconventional produced waters (PWs) with a focus on minimizing the generation of solid waste. The feasibility of MLD was evaluated using OLI, a water chemistry software, to model thermal desalination of unconventional PWs from the Delaware Basin in New Mexico (NM). Desalination was theoretically terminated at an evaporation point before halite $(\mathrm{NaCl})$ saturation in the residual brine. Results of this study showed that selectively targeting a subset of higher flow rate and lower TDS wells/centralized tank batteries (CTBs) could yield up to $76 \%$ recovery of distillate while generating minimal solid waste. Using a selective MLD approach did reduce the quantity of distillate recovered when compared with ZLD, and left a reduced volume of residual brine which has to be managed as a liquid waste. However, selective MLD also greatly reduced the amount of solid waste. The use of a ZLD approach yielded incrementally greater quantities of distillate but at the cost of large quantities of difficultto-manage highly soluble waste. Simulation results showed that waste generated before $\mathrm{NaCl}$ precipitation was primarily composed of insoluble compounds such as calcite, barite and celestite, which can be disposed in conventional landfills. This study also found a simple empirical linear relationship between TDS and distillate recovery, thus allowing a non-expert to rapidly estimate potential distillate recovery for a given starting PW quality.
\end{abstract}

Keywords: produced water treatment; thermal desalination; minimum liquid discharge (MLD); beneficial use; solid waste minimization; halite precipitation

\section{Introduction}

Unconventional Oil \& Gas (O\&G) operations across the US, including the Delaware Basin in New Mexico, are expected to generate large quantities of produced water (PW). Currently, the O\&G industry has two options for managing PW, which may be termed as business-as-usual or baseline options. These two options are (1) injection into salt water disposal (SWD) wells and (2) minimal treatment to produce a clean brine followed by its reuse in on-going $O \& G$ operations. An alternate option which envisages the use of desalinated PW for various beneficial purposes within the O\&G industry (e.g., cooling water) and/or outside the O\&G industry (e.g., surface discharge, agriculture use) has recently gained increased attention [1]. The drivers for this increased attention include potential constraints to the abovementioned baseline options and/or alleviation of regional water scarcity, which can be achieved by either substituting industry withdrawals of fresh and brackish water with recovered distillate and/or augmenting local freshwater supplies. Any potential risk arising from the use of distillate within the O\&G industry can be considered low, given that the distillate will not be introduced into the environment. However, lack of adequate information on PW and distillate composition was stated to be a major factor that could prevent beneficial use of distillate outside the O\&G industry [2]. 
Desalination of PW has several challenges including high energy requirements, potential toxicity associated with organics in the desalinated PW and generation of large quantities of highly soluble solid waste. In a recent study, it was estimated that desalination of approximately $500,000 \mathrm{bbl} / \mathrm{d}$ containing $295,500 \mathrm{mg} / \mathrm{L}$ total dissolved solids (TDS) to $80 \%$ evaporation by volume would generate approximately $0.31 \mathrm{M} \mathrm{lb} / \mathrm{d}$ of sparingly soluble waste (primarily gypsum and celestite) and $31.5 \mathrm{M} \mathrm{lb} / \mathrm{d}$ of $\mathrm{NaCl}$ ( $5.75 \mathrm{M}$ tons/year) [3]. For comparison, annual US salt production in 2020 was $39 \mathrm{M}$ tons, and salt production from the desalination of $500,000 \mathrm{bbl} / \mathrm{d} \mathrm{PW}$ would equal approximately $15 \%$ of US production [4] If run in a zero liquid discharge (ZLD) mode by complete evaporation of the residual brine, an additional $15.8 \mathrm{M} \mathrm{lb} / \mathrm{d}$ of mixed waste would be generated. Further, with the exception of gypsum and celestite, most of the solid waste generated ( $>99 \%$ by mass) was comprised of highly soluble salts such as $\mathrm{NaCl}$. The generation of such large quantities of difficult-to-manage, highly soluble solid waste is considered to be a major challenge for the implementation of desalination of unconventional PWs.

According to a recent report, the volume of water used for fracturing by the $O \& G$ industry in New Mexico was $311.4 \mathrm{M} \mathrm{bbl} / \mathrm{yr}(0.85 \mathrm{M} \mathrm{bbl} / \mathrm{d})$ and $\mathrm{PW}$ generated was $1240 \mathrm{M} \mathrm{bbl} / \mathrm{yr}$ (3.4 M bbl/d) in 2019 [5]. The same report citing NM Oil Conservation Division data [6] stated that the source of water for fracturing operations in Eddy and Lea counties (November and December 2020) was 13, 47 and 40\% from fresh (TDS $<1000 \mathrm{mg} / \mathrm{L}$ ), brackish (TDS between 1000 and 10,000 mg/L) and PW, respectively. Assuming that operations in Eddy and Leah counties are approximately representative of state-wide unconventional $O \& G$ operations in NM, total fresh and brackish water used by the $O \& G$ industry in NM (in 2019) would be approximately 111,000 and 400,000 bbl/d, respectively. While current water use is likely higher than in 2019, a sufficiently large quantity of PW is available in NM such that enough PW can be desalinated to either substantially or completely offset industry withdrawals of fresh and brackish water in NM, leaving these resources for use by local consumers.

\subsection{Concepts—Minimum vs. Zero Liquid Discharge}

The main difference between minimum liquid discharge (MLD) and ZLD zero liquid discharge (ZLD) desalination options is that MLD seeks to minimize solid waste generation at a lower water recovery when compared with ZLD, which seeks to maximize water recovery but also generates large quantities of difficult-to-manage solid waste (primarily $\mathrm{NaCl}$, in the case of desalination of unconventional O\&G PWs) $[7,8]$. Panagopolous and Haralambous [9] noted that for seawater desalination (TDS-35,000 mg/L), an MLD process recovered up to $95 \%$ freshwater (distillate) at an energy consumption of $5.4 \mathrm{kWh} / \mathrm{m}^{3}$ whereas a ZLD system was able to recover up to $100 \%$ freshwater but required almost twice the energy input of an MLD system $\left(10.43 \mathrm{kWh} / \mathrm{m}^{3}\right)$. Therefore, from the perspective of energy consumption and waste generation, MLD systems with lower water recovery can be more attractive than ZLD systems.

If distillate obtained from desalination of $P W$ is used within the O\&G industry, it may not require further treatment as environmental aspects/concerns typically associated with internal use may not pose an issue. However, significant research is required before distillate can be beneficially used outside the $O \& G$ industry. PW can vary both spatially and temporally [2] and therefore, the composition of distillate obtained from varying PW quality may be expected to vary as well. Environmental concerns regarding distillate use for beneficial purposes outside the O\&G industry is mostly centered on the composition of organic compounds that can partition into the distillate as a result of desalination. Therefore, the composition of the organics present in distillate and potential toxicity considerations, if any, will have to be determined prior to beneficial use. Physico-chemical as well as biological treatment technologies can be employed to remove/destroy organics present in distillate and reduce any residual organics to within regulatory compliance limits. Note that the characterization of distillate obtained from desalination and evaluation of any 
potential toxicity for beneficial use outside the O\&G industry is not within the scope of this research study.

\subsection{Objectives of Research}

As noted in the discussion above, the objective of this case study was to use an MLD approach to estimate distillate recovery via desalination of unconventional PWs, where the desalination process was terminated at the point just prior to halite $(\mathrm{NaCl})$ saturation.

Specific tasks associated with this study are noted below.

1. Develop a conceptual desalination process using OLI water chemistry software [10] that allows identification of the evaporation point at which the residual brine is saturated with $\mathrm{NaCl}$;

2. Estimate total solid waste generation prior to $\mathrm{NaCl}$ precipitation;

3. Determine if a simple correlation can be used to predict distillate recovery.

\section{Materials and Methods}

\subsection{Produced Water Quality Used in OLI Modeling}

General water quality parameters and major ions for 83 wells and/or centralized tank batteries (CTBs) from XTO operations in NM are summarized in Table 1 below. Given that the objective of this research effort was to predict the point of $\mathrm{NaCl}$ precipitation, only major ions listed in Table 1 below were considered for input to the OLI model. As a quality control check, the cation-anion balance for each PW quality was calculated; this balance was generally within a relative percent difference of $30 \%$. Average TDS and flow rate for the 83 wells/locations dataset were approximately 209,000 mg/L (range of 39,000 to $310,000 \mathrm{mg} / \mathrm{L}$ ) and $800 \mathrm{bbl} / \mathrm{d}$ (range of 3 to $7000 \mathrm{bbl} / \mathrm{d}$ ), respectively. 
Table 1. Summary of produced water quality used in this study (from XTO operations in NM).

\begin{tabular}{|c|c|c|c|c|c|c|c|c|c|c|c|c|c|c|c|c|}
\hline & Water & TDS & $\mathrm{pH}$ & $\mathrm{Na}$ & $\mathbf{K}$ & $\mathrm{Ca}$ & $\mathrm{Mg}$ & Sr & Ва & $\mathrm{Fe}$ & Mn & $\mathbf{L i}$ & $\mathrm{Cl}$ & $\mathrm{Br}$ & $\mathrm{SO}_{4}$ & $\mathrm{HCO}_{3}$ \\
\hline & bbl/d & $\mathrm{mg} / \mathrm{L}$ & su & $\mathrm{mg} / \mathrm{L}$ & $\mathrm{mg} / \mathrm{L}$ & $\mathrm{mg} / \mathrm{L}$ & $\mathrm{mg} / \mathrm{L}$ & $\mathrm{mg} / \mathrm{L}$ & $\mathrm{mg} / \mathrm{L}$ & $\mathrm{mg} / \mathrm{L}$ & $\mathrm{mg} / \mathrm{L}$ & $\mathrm{mg} / \mathrm{L}$ & $\mathrm{mg} / \mathrm{L}$ & $\mathrm{mg} / \mathrm{L}$ & $\mathrm{mg} / \mathrm{L}$ & $\mathrm{mg} / \mathrm{L}$ \\
\hline \multicolumn{17}{|c|}{ Delaware Formation (40 wells) } \\
\hline Average & 1017 & 248,785 & 6.4 & 64,015 & 1707 & 24,110 & 2980 & 1089 & 4 & 33 & 7 & 36 & 156,227 & 1366 & 194 & 127 \\
\hline Median & 522 & 262,363 & 6.3 & 67,805 & 1899 & 27,965 & 3304 & 1141 & 4 & 28 & 7 & 40 & 165,282 & 1492 & 112 & 49 \\
\hline Min & 11 & 38,903 & 5.0 & 13,307 & 209 & 341 & 70 & 92 & 0 & 0 & 0 & 12 & 22,200 & 41 & 41 & 12 \\
\hline Max & 7000 & 355,107 & 7.4 & 83,690 & 2529 & 31,656 & 4137 & 1903 & 11 & 80 & 17 & 53 & 253,125 & 2467 & 664 & 805 \\
\hline \multicolumn{17}{|c|}{ Bone Springs/Bone Sands Formation (35 wells) } \\
\hline Average & 392 & 169,091 & 6.6 & 54,022 & 1231 & 8484 & 1230 & 448 & 2 & 31 & 2 & 68 & 104,065 & 1000 & 395 & 411 \\
\hline Median & 196 & 154,574 & 6.6 & 56,552 & 1259 & 5216 & 774 & 296 & 1 & 27 & 1 & 56 & 94,292 & 898 & 357 & 244 \\
\hline Min & 9 & 44,225 & 5.5 & 15,380 & 209 & 405 & 69 & 102 & 0 & 1 & 0 & 12 & 26,579 & 196 & 90 & 12 \\
\hline Max & 3000 & 268,913 & 7.5 & 73,018 & 1763 & 31,793 & 3491 & 1309 & 9 & 76 & 15 & 129 & 169,486 & 1855 & 1420 & 952 \\
\hline \multicolumn{17}{|c|}{ Devonian Formation (3 wells) } \\
\hline Average & 2857 & 259,374 & 5.7 & 62,978 & 2070 & 27,169 & 3341 & 1349 & 3 & 31 & 8 & 34 & 164,210 & 1786 & 261 & 24 \\
\hline Min & 19 & 234,664 & 5.5 & 56,039 & 1706 & 25,070 & 2798 & 937 & 3 & 27 & 7 & 23 & 145,567 & 1546 & 107 & 12 \\
\hline Max & 6000 & 287,894 & 6.2 & 70,817 & 2552 & 28,777 & 4017 & 1591 & 4 & 34 & 8 & 42 & 184,408 & 2025 & 517 & 37 \\
\hline \multicolumn{17}{|c|}{ Upper Avalon Formation (3 wells) } \\
\hline Average & 104 & 213,433 & 6.4 & 70,500 & 1569 & 11,130 & 1825 & 507 & 1 & 36 & 4 & 52 & 127,822 & 1366 & 880 & 728 \\
\hline Median & 36 & 213,631 & 6.4 & 70,394 & 1626 & 9735 & 1625 & 534 & 2 & 22 & 4 & 46 & 128,021 & 1366 & 880 & 878 \\
\hline Min & 3 & 205,074 & 6.1 & 66,935 & 1432 & 5004 & 1168 & 220 & 0 & 20 & 1 & 44 & 125,574 & 1251 & 786 & 220 \\
\hline Max & 274 & 221,594 & 6.6 & 74,172 & 1649 & 18,652 & 2681 & 766 & 2 & 66 & 5 & 67 & 129,872 & 1481 & 973 & 1086 \\
\hline \multicolumn{17}{|c|}{ Wolfcamp Formation (2 wells) } \\
\hline Average & 1324 & 77,139 & 6.8 & 25,678 & 609 & 2394 & 388 & 596 & 3 & 15 & 0 & 52 & 47,659 & 336 & 208 & 195 \\
\hline Median & \multicolumn{16}{|c|}{ Not applicable } \\
\hline Min & 1200 & 70,784 & 6.5 & 22,760 & 585 & 2151 & 300 & 548 & 3 & 6 & 0 & 35 & 44,501 & 304 & 180 & 171 \\
\hline Max & 1447 & 83,493 & 7.0 & 28,597 & 632 & 2637 & 477 & 644 & 4 & 24 & 1 & 69 & 50,817 & 367 & 236 & 220 \\
\hline
\end{tabular}




\subsection{OLI Modeling}

Water quality for each of the 83 wells/CTBs was input into OLI (OLI Systems Inc., Parsippany, NJ, USA), and the first step in modeling was to reconcile the cation-anion balance. Imbalances in cations and anions were adjusted by the addition of sodium and chloride ions, respectively, to ensure an electrically neutral solution. Following reconciliation, a vapor survey was performed at increments of $1 \%$ evaporation increments (by mole \%) at a pressure of $1 \mathrm{Atm}$ and a starting temperature of $25^{\circ} \mathrm{C}$. In the output file, the first point of $\mathrm{NaCl}$ precipitation was identified, and the distillate recovered and the total solid waste produced was noted at the evaporation point immediately preceding $\mathrm{NaCl}$ precipitation. Total solid waste generated $(\mathrm{lb} / \mathrm{d})$ was then calculated by multiplying the unit waste produced (in lb/bbl) by the flow rate for the individual well/CTB (bbl/d).

An example of the MLD approach for a hypothetical PW is shown in Figure 1, where it can be seen that most of the solid waste produced during desalination is comprised of highly soluble $\mathrm{NaCl}$. If desalination were to be stopped just before the onset of $\mathrm{NaCl}$ precipitation, then solid waste generation can be minimized. In this example, $\mathrm{NaCl}$ precipitation started at $69 \%$ distillate recovery, and therefore, potential water recovery for this hypothetical PW was assumed to be $68 \%$ and the total mass of precipitated solids at $68 \%$ distillate recovery was then used to estimate solid waste generation.

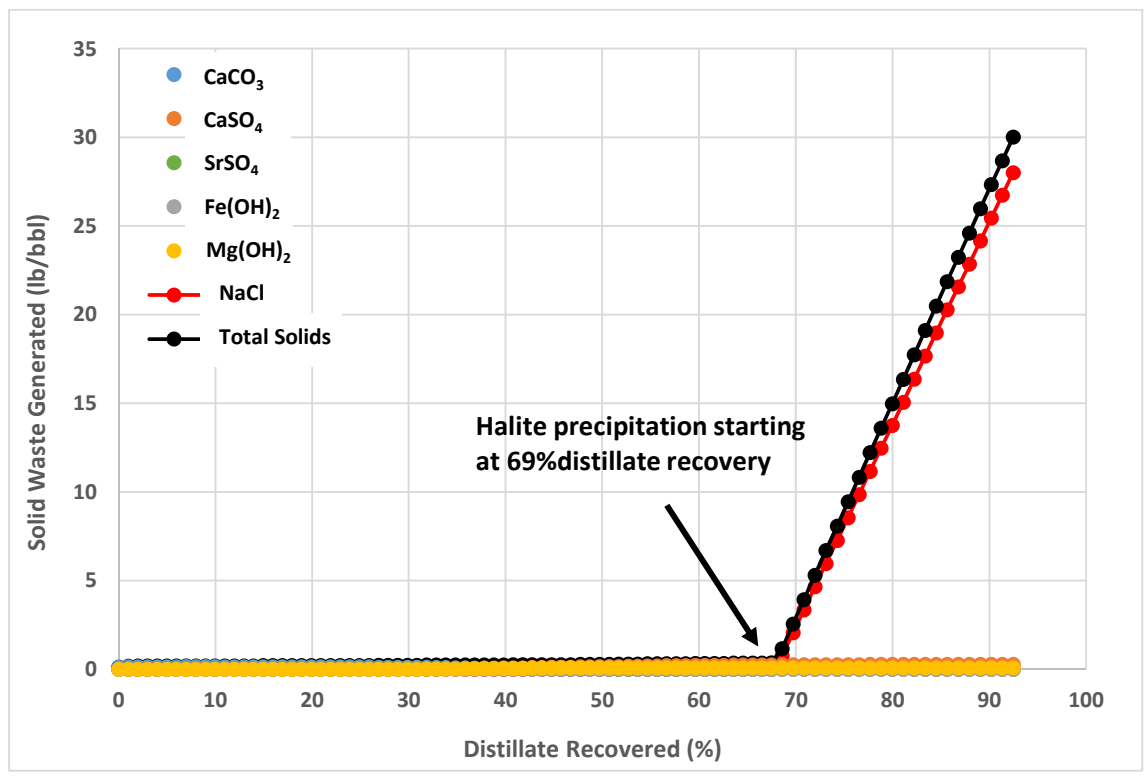

Figure 1. Solids production as a function of distillate recovered during desalination of PW.

As more distillate or clean water is recovered from PW, TDS in the remaining PW (or brine) continues to increase eventually reaching the point of $\mathrm{NaCl}$ saturation. The focus of this paper is to understand the chemical composition of the remaining PW with the objective of predicting the point of halite saturation. The chemical composition of the remaining brine is a function of the amount of clean water abstracted or recovered from the original PW and does not depend on the technology employed for desalination. In other words, the analysis and conclusions presented in this paper are independent of the technology employed for desalination.

\section{Results and Discussion}

\subsection{Distillate Recovery}

Simulated distillate recovery using an MLD approach (terminating desalination prior to $\mathrm{NaCl}$ precipitation) as a function of PW TDS is shown in Figure 2. As expected, the amount of distillate recovered is higher for PWs with lower TDS. Considering all 83 wells with an average TDS of $209,000 \mathrm{mg} / \mathrm{L}$, distillate recovery averaged approximately $41 \%$ 
(range of 11 to $88 \%$ ). A linear correlation between percent distillate recovered and PW TDS was also developed as shown in Figure 2. Such a simple correlation can enable a non-expert to rapidly screen PW qualities and estimate potential for distillate recovery without the need for water chemistry/modelling expertise. A similarly strong correlation was found between distillate recovery and chloride concentration (see Figure 3). The interrelationship between TDS/chloride and $\mathrm{NaCl}$ precipitation is not entirely unexpected given that chloride is the predominant ion in PW, constituting approximately $60 \%$ of the total ions in solution.

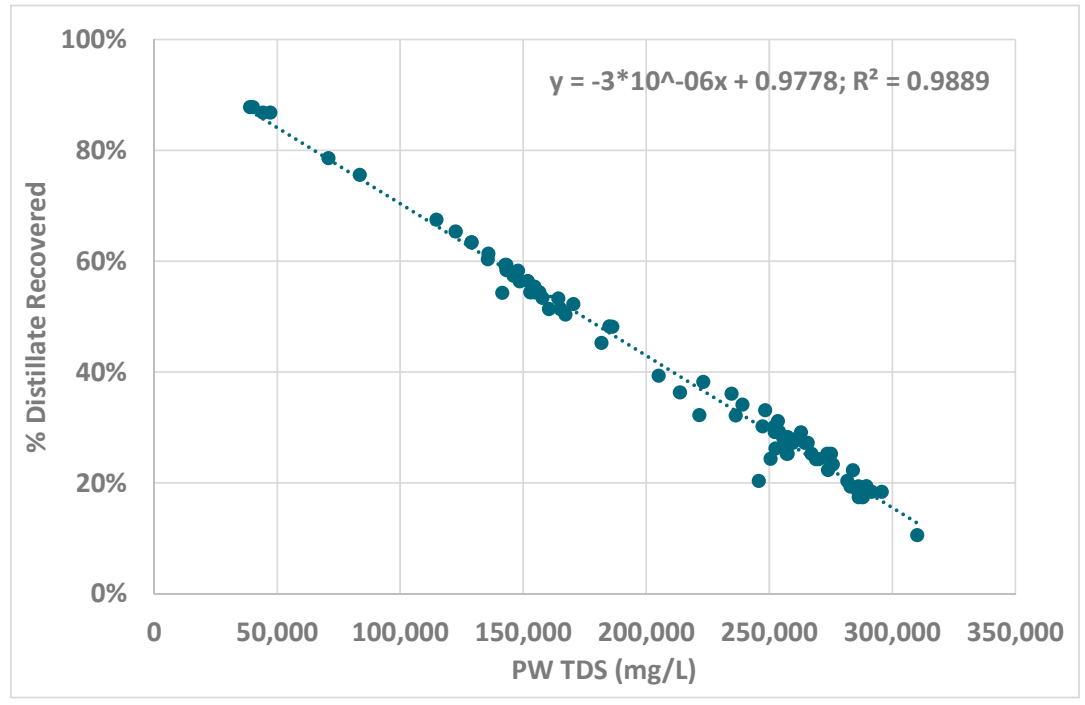

Figure 2. Modelled distillate recovery as a function of PW TDS using an MLD approach.

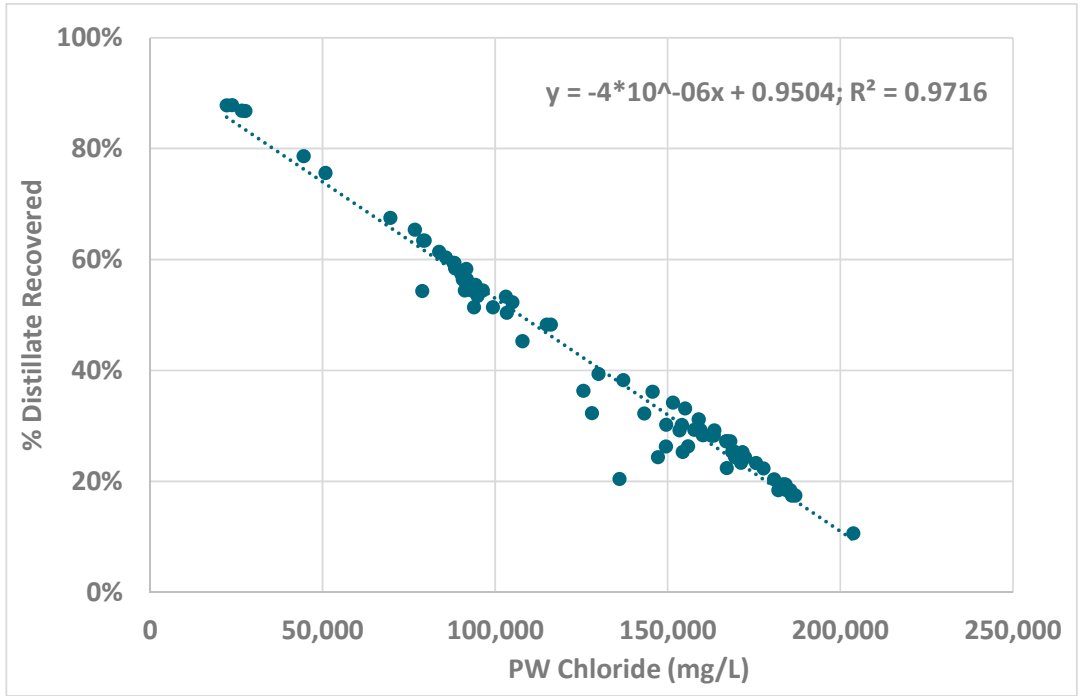

Figure 3. Modelled distillate recovery as a function of PW Chloride using an MLD approach.

\subsection{Solid Waste Generation}

Solid waste generated using the MLD approach is shown in Figure 4. Waste generation averaged approximately $0.15 \mathrm{lbs} / \mathrm{bbl} \mathrm{PW}$ desalinated (range of 0.002 to $0.68 \mathrm{lbs} / \mathrm{bbl}$ ). Unlike distillate recovery, correlation between waste generated (up to the point of $\mathrm{NaCl}$ precipitation) and TDS was poor; however, waste generated seemed to generally trend lower with increasing TDS. Up to the point of $\mathrm{NaCl}$ precipitation, the waste generated is comprised of sparingly soluble solids such as calcite, barite and celestite. Management of such sparingly soluble waste is relatively straightforward and typically comprises 
settling/filtering the solids generated, followed by thickening and dewatering steps to produce a high solids content cake, which can then be disposed in a conventional (nonhazardous) landfill.

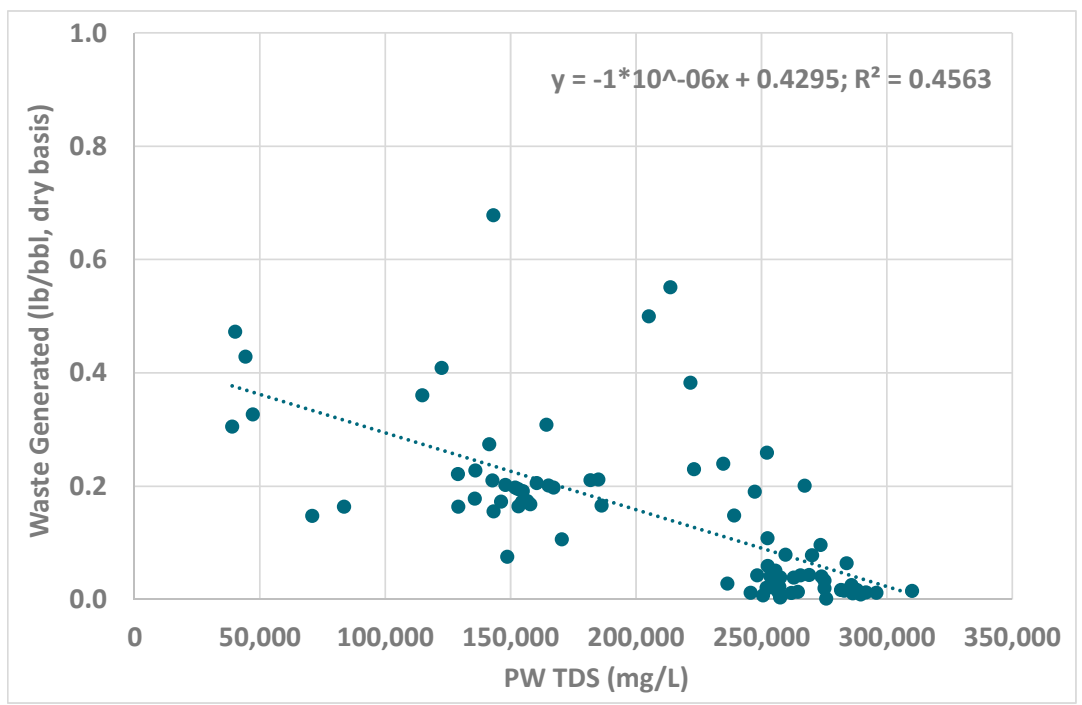

Figure 4. Estimated solid waste generated $(\mathrm{lb} / \mathrm{bbl})$ via MLD as a function of PW TDS.

\subsection{Selective MLD—Focussing Desalination Efforts on High Flow Rate and Low TDS PWs}

A further refinement of the MLD approach for PW desalination described in this paper is to consider limiting desalination treatment to a subset of high flow rate wells only or an even smaller subset of high flow rate wells with lower TDS. The objective of evaluating such a selective MLD approach is to determine the feasibility of recovering substantial distillate for beneficial use while minimizing the volume of PW that needs to be treated/desalinated, and therefore, minimize the cost of desalination. For the purpose of this analysis, the flow rate cut-off was arbitrarily set at $450 \mathrm{bbl} / \mathrm{d}$, which decreased the number of wells/CTBs from 83 to 36 while still accounting for $89 \%$ of the total flow. Similarly, TDS limits was arbitrarily set at $<250,000 \mathrm{mg} / \mathrm{L},<180,000 \mathrm{mg} / \mathrm{L}$ and $<150,000 \mathrm{mg} / \mathrm{L}$, which reduced the number of candidate wells/CTBs to 17,11 and 8 , respectively. Water recovery and waste generation using such a selective MLD approach are shown in Table 2.

Table 2. Utilizing a selective MLD approach to optimize distillate recovery.

\begin{tabular}{|c|c|c|c|c|c|}
\hline $\begin{array}{l}\text { MLD Desalination } \\
\text { Scenario }\end{array}$ & \# of Wells & Total Flow Rate & Avg. TDS & $\begin{array}{l}\text { Distillate } \\
\text { Recovered }\end{array}$ & $\begin{array}{l}\text { Total Solid } \\
\text { Waste }\end{array}$ \\
\hline & & $\mathbf{b b l} / \mathbf{d}$ & $\mathrm{mg} / \mathrm{L}$ & bbl/d (\%) & $\mathrm{lb} / \mathrm{d}$ \\
\hline No flow rate or TDS limit & 83 & 66,556 & $\begin{array}{c}208,867 \\
\min : 39,000 \\
\max : 310,000\end{array}$ & $\begin{array}{l}27,003 \\
(41 \%)\end{array}$ & 12,216 \\
\hline $\begin{array}{c}\text { Subset of high flow rate } \\
\text { wells; } \\
\text { no TDS limit }\end{array}$ & 36 & 58,916 & $\begin{array}{c}213,520 \\
\min : 39,000 \\
\max : 310,000\end{array}$ & $\begin{array}{l}23,172 \\
(39 \%)\end{array}$ & 10,823 \\
\hline $\begin{array}{c}\text { Subset of high flow rate } \\
\text { wells; } \\
\text { TDS }<250,000 \mathrm{mg} / \mathrm{L}\end{array}$ & 17 & 34,764 & $\begin{array}{c}148,594 \\
\min : 39,000 \\
\max : 248,000\end{array}$ & $\begin{array}{l}19,903 \\
(57 \%)\end{array}$ & 10,126 \\
\hline $\begin{array}{c}\text { Subset of high flow rate } \\
\text { wells; } \\
\text { TDS }<180,000 \mathrm{mg} / \mathrm{L}\end{array}$ & 11 & 27,213 & $\begin{array}{c}103,662 \\
\min : 39,000 \\
\max : 170,000\end{array}$ & $\begin{array}{l}19,076 \\
(70 \%)\end{array}$ & 9029 \\
\hline $\begin{array}{c}\text { Subset of high flow rate } \\
\text { wells; } \\
\text { TDS }<150,000 \mathrm{mg} / \mathrm{L}\end{array}$ & 8 & 25,317 & $\begin{array}{c}82,580 \\
\min : 39,000 \\
\max : 143,000\end{array}$ & $\begin{array}{l}19,303 \\
(76 \%)\end{array}$ & 8729 \\
\hline
\end{tabular}


Restricting desalination to wells with a flow rate greater than $450 \mathrm{bbl} / \mathrm{d}$ reduced PW volume processed/desalinated by $11 \%$ (from 66,556 to $58,916 \mathrm{bbl} / \mathrm{d}$ ) while decreasing distillate recovered by $14 \%$ (from 27,003 to $23,172 \mathrm{bbl} / \mathrm{d}$ ). Therefore, selectively desalinating higher flow rate wells with an MLD approach did not result in significant efficiency in distillate recovery because the higher flow rate wells had nearly the same average TDS as that of the larger dataset. However, using a TDS cut-off for desalination did result in greater efficiency in distillate recovery. For example, restricting desalination of the high flow rate wells to those with TDS less than 150,000 $\mathrm{mg} / \mathrm{L}$ reduced the volume of PW requiring desalination by $62 \%$ (from 66,556 to $25,317 \mathrm{bbl} / \mathrm{d}$ ) but with a much smaller reduction $29 \%$ reduction in distillate recovered (from 27,003 to $19,303 \mathrm{bbl} / \mathrm{d}$ ). Waste generation on a normalized basis, however, was much higher; $0.18 \mathrm{lb} / \mathrm{bbl}$ vs. $0.34 \mathrm{lb} / \mathrm{bbl}$ for all wells vs. those with a cut-off of 150,000 mg/L TDS, respectively. However, as will be shown later, overall waste generation is still much lower than that produced by a ZLD process.

In summary, selective application of an MLD approach was predicted to yield substantial volumes of distillate for beneficial use while greatly reducing the volume of PW that would have to be processed via desalination as well as greatly minimizing waste generation.

\subsection{Comparison of Selective MLD and Traditional Desalination Approaches}

To illustrate the benefits of an MLD vs. ZLD approach, three scenarios were evaluated as described below, and the results are shown in Table 3.

Selective MLD—-high flow rate and low TDS PWs:

1. Only high flow rate wells with average TDS $\leq 100,000 \mathrm{mg} / \mathrm{L}$ will be selectively targeted for desalination; treatment will be at the well-pad level.

2. An MLD approach will be used by terminating desalination just before $\mathrm{NaCl}$ precipitation; small quantities of largely insoluble waste will be generated.

3. Residual brine will be injected in SWD wells.

Selective ZLD (Evaporation and Crystallization)—high flow rate and low TDS PWs:

1. Only high flow rate wells with average TDS $\leq 100,000 \mathrm{mg} / \mathrm{L}$ will be selectively targeted for desalination; treatment will be at the well-pad level.

2. The desalination process will be operated beyond the point of halite precipitation up to practical limits of operation.

3. Any residual brine will be evaporated to dry solids (zero liquid waste); all of the TDS in PW will precipitate out of solution; solid waste will comprise predominantly soluble salts.

Large-Scale ZLD (Crystallization)—no restriction on flow rate or TDS:

1. PW will be desalinated regardless of TDS or flow rates to obtain maximum distillate volumes; treatment will be at CTBs.

2. The desalination process will be operated beyond the point of halite precipitation up to practical limits of operation.

3. Any residual brine will be evaporated to dry solids (zero liquid waste); all of the TDS in PW will precipitate out of solution; solid waste will comprise predominantly soluble salts.

As can be seen from the above analysis, the use of a selective MLD approach to PW desalination is far more advantageous than either ZLD approaches. Using an MLD approach does result in lower recovery of distillate and still leaves a liquid waste that requires disposal. However, this liquid waste constitutes a fraction of the original PW volume, and can be transported using existing infrastructure to SWD wells for disposal. Further, the liquid waste/saturated brine waste may also offer potential opportunities for recovery of valuable elements such as lithium, bromine and other elements of commercial value prior to disposal [3]. 
Table 3. Comparison of Selective MLD and Selective and Large-Scale ZLD approaches for PW management.

\begin{tabular}{|c|c|c|c|c|}
\hline Parameter & Units & Selective MLD & Selective ZLD & Large-Scale ZLD \\
\hline Attributes & & $\begin{array}{ll}\text { - } & \text { Focus on low TDS/high flow rate PW } \\
\text { - } & \text { MLD; stop before } \mathrm{NaCl} \text { precipitation } \\
\text { - } & \text { Liquid waste to disposal (SWD) } \\
& \text { Implemented on a well-pad level }\end{array}$ & $\begin{array}{ll}\text { - } & \text { Focus on low TDS/high flow rate } \\
& \text { PWs } \\
\text { - } & \text { Evaporator/Crystallizer } \\
\text { - } & \text { Liquid waste evaporated to } \\
\text { dryness } \\
\text { - } \\
\text { Implemented on a well-pad level }\end{array}$ & $\begin{array}{ll}\text { - } & \text { No restriction on flow rate or TDS } \\
\text { - } & \text { Liquid waste evaporated to } \\
& \text { dryness } \\
\text { - } & \text { Implemented at CTBs }\end{array}$ \\
\hline Average TDS & $\mathrm{mg} / \mathrm{L}$ & $<100,000$ & $<100,000$ & $\begin{array}{c}210,000 \\
\text { (average of } 83 \text { well dataset) }\end{array}$ \\
\hline Distillate Recovered & $\%$ & $\begin{array}{c}70 \\
\text { (this study) }\end{array}$ & $\begin{array}{c}90 \\
\text { (estimated from Ghurye, et al. [3]) }\end{array}$ & $\begin{array}{c}80 \\
\text { (estimated from Ghurye, et al. [3]) }\end{array}$ \\
\hline Liquid Waste Generated & $\mathrm{bbl} / \mathrm{d}$ & $\begin{array}{c}30,000 \\
\text { (injected into SWD wells) }\end{array}$ & $\begin{array}{c}0 \\
\text { (zero liquid waste) }\end{array}$ & $\begin{array}{c}0 \\
\text { (zero liquid waste) }\end{array}$ \\
\hline \multicolumn{5}{|l|}{ Solid Waste Generated } \\
\hline $\mathrm{NaCl}$ & tons $/ \mathrm{d}$ & 0 & 1067 & 2242 \\
\hline $\begin{array}{l}\text { Mixed Waste (liquid waste } \\
\text { evaporated to dryness) }\end{array}$ & tons $/ \mathrm{d}$ & 0 & 536 & 1125 \\
\hline Solid Waste Characteristics & & $\begin{array}{ll}\text { - } & \text { Sparingly soluble } \\
\text { - } & \text { Disposal in conventional landfills }\end{array}$ & $\begin{array}{l}\text { - Highly soluble waste } \\
\text { - } \quad \text { disy need hazardous waste } \\
\text { disposal in specialized landfills }\end{array}$ & $\begin{array}{l}\text { - Highly soluble waste } \\
\text { - May need hazardous waste } \\
\text { disposal in specialized landfills }\end{array}$ \\
\hline $\begin{array}{c}\text { Solid Waste Transportation } \\
\text { (@ } 21 \text { tons/truck) }\end{array}$ & trucks/d & $<1$ & 77 & 161 \\
\hline
\end{tabular}


A ZLD approach, on the other hand produces no liquid waste and recovers 15-30\% more distillate than MLD. However, this incremental distillate recovery is offset by the large quantity of highly soluble, and therefore, difficult-to-manage solid waste. Based on the quantity of solid waste generated, ZLD will also incur higher transportation costs than MLD. Further, there are no examples of solid landfills that accept large quantities of highly soluble waste. If implemented, the use of ZLD will therefore require research into designing specialized landfills capable of sustainably sequestering such highly soluble wastes.

\subsection{Considerations for the Application of a Selective MLD Approach to Desalination of Unconventional PWs}

As can be seen from the discussion above, the two main parameters required to implement a selective MLD approach are flow rate and TDS. While flow rate data is generally automated and readily available, obtaining the TDS of PW requires a sample to be sent to a laboratory for analysis. To enable rapid decision making, the use of conductivity as a surrogate for TDS should be investigated. For example, the conductivity of PWs from a representative number of wells can be measured in the field and a split sample can be sent off-site for TDS analysis. A correlation can then be developed relating conductivity to TDS. Rapidly deployable (mobile) and modular desalination technologies will have to be identified and their performance will have validated via bench and/or pilot studies. The accuracy of OLI modeling and waste generation estimates should also be verified during technology validation studies.

\subsection{Considerations for Beneficial Use of Desalinated Water within and Outside the OEG Industry}

A hierarchy of beneficial uses should be developed based on use-specific risk and exposure to environmental receptors based on initial distillate quality. For example, although low-TDS/fresh water quality is not required, use for fracturing operations within the O\&G industry could pose the lowest risk as the distillate (and any unidentified constituents contained in it) will not be introduced into the environment. Next, other uses within O\&G industry for purposes such as dust control (in the vicinity of well pads) and cooling water should be explored, and potential risks and distillate treatment options should be identified to mitigate any identified risks. Thus, a combination of uses of desalinated PW within the O\&G industry can substantially or completely offset industry's fresh and brackish water withdrawals, leaving these natural resources for use by local consumers.

Once this internal demand is substantially or fully satisfied, beneficial uses outside the $O \& G$ industry can be contemplated. For such beneficial use, desalinated PW should be considered a new source water that requires thorough investigation to enable sciencebased regulations governing its use. Given that the composition of PW is both spatially and temporally variable, the quality of desalinated PW may be expected to vary as well. Therefore, both PW and distillate quality should be adequately characterized and usebased environmental receptors should be identified to develop a robust toxicology and risk framework.

Finally, if there is no proximate demand for desalinated PW and conveyance to the location of demand is not economically feasible, releasing the distillate as steam into the atmosphere can be explored. The presence and potential environmental ramifications of distillate constituents in such emissions will have to be addressed prior to release. In such a scenario, even if distillate is not captured for beneficial use, a substantial reduction in the volume of PW can be achieved, which can be advantageous in locations where disposal of PW via SWD may face constraints.

\section{Conclusions}

The findings of this study demonstrated the advantages of using a selective MLD desalination approach for management of unconventional PWs. A comparison between selective MLD, with a focus on desalination of high flow rate and lower TDS wells, was determined to be a superior option to selective and large-scale ZLD. Sufficient distillate can be obtained from a selective MLD approach to offset the O\&G industry's withdrawals 
of fresh and brackish groundwater in NM. By selective application of MLD, the waste generated from desalination of PW can be minimized, thus addressing one of the major challenges associated with desalination of unconventional O\&G PWs.

Further, a simple correlation between PW TDS and distillate recovery can be used to rapidly evaluate the feasibility of a selective MLD approach as an alternative option for management of unconventional PWs. Although this study focused on PW in NM, the selective MLD approach used in this study may be applicable to other unconventional PWs as well.

A hierarchy of beneficial uses should be developed and lower risk options identified for initial use of desalinated PW. As research progresses and adequate characterization of the composition of PW and distillate is available and a robust risk assessment framework is developed, other beneficial uses can be studied to ensure environmentally responsible use of desalinated PW.

\section{Recommendations for Future Research}

As seen from the above discussion, the use of an MLD approach for desalination of $\mathrm{PW}$ is a promising option that can complement the baseline options currently used by the O\&G industry to manage unconventional PWs. However, significant research is needed to ascertain the feasibility of, and operationalize, an MLD approach to desalination of unconventional PWs. Based on the results of this study, the following recommendations are offered for future research.

1. The results obtained from OLI modeling of PW should be verified at the bench and/or pilot scale to confirm modeled distillate recovery and solid waste generated as a function of PW TDS. Further, to implement a selective MLD approach will require real-time data on PW flow rates and TDS. An accurate correlation between TDS and conductivity will have to be developed to enable rapid selection of potential wells/well pads for implementation of an MLD approach.

2. Mobile and rapidly deployable, modular desalination technologies will have to be identified/developed and validated. Technologies that require little to no pretreatment prior to desalination can provide operations flexibility and reduce costs. Further, emerging technologies such as MD, which have the potential to use waste and/or renewable sources of energy, should also be explored to enable cost-effective desalination of unconventional PWs.

3. To enable beneficial use outside the O\&G industry, the composition of desalinated PW will have to be adequately characterized to ensure that potential environmental and human health impacts, if any, are mitigated to acceptable toxicology and/or regulatory end-points.

Funding: This project was funded by the ExxonMobil Upstream Research Company.

Institutional Review Board Statement: Not applicable.

Informed Consent Statement: Not applicable.

Data Availability Statement: The data presented in this study is available on request from the corresponding author.

Acknowledgments: The author would like to acknowledge the following individuals for providing an expert review and/or editorial comments for this manuscript: Bryan Hedgpeth (ExxonMobil Biomedical Sciences) and Carlos Galdeano and Eric J. Febbo (ExxonMobil Upstream Research Company).

Conflicts of Interest: The authors declare that they have no known competing financial interests or personal relationships that could have appeared to influence the work reported in this paper. 


\section{References}

1. State of New Mexico and US EPA. Oil and Natural Gas Produced Water Governance in the State of New Mexico-Draft White Paper. 2018. Available online: https://www.epa.gov/sites / production/files/2018-11/documents/oil_and_natural_gas_produced_ water_governance_in_the_state_of_new_mexico_draft_white_paper_508.pdf (accessed on 30 June 2021).

2. Scanlon, B.R.; Reedy, R.C.; Xu, P.; Engle, M.; Nicot, J.; Yoxtheimer, D.; Yang, Q.; Ikonnikova, S. Can we beneficially reuse produced water from oil and gas extraction in the U.S.? Sci. Total. Environ. 2020, 717, 137085. [CrossRef] [PubMed]

3. Ghurye, G.L.; Mishra, D.; Lucas, L. Thermal desalination of produced water-An analysis of the partitioning of constituents into product streams and its implications for beneficial use outside the O\&G industry. Water 2021, 13, 1068. [CrossRef]

4. USGS, National Minerals Information Center, Salt Statistics and Information. 2021. Available online: https://pubs.usgs.gov/ periodicals/mcs2021/mcs2021-salt.pdf (accessed on 27 July 2021).

5. Thomson, B.M.; Chermak, J.M. Analysis of the relationship water, oil \& gas in New Mexico: Investigation of Past and Future Trends. NM WRRI Technical Completion Report No. 390, 2021, New Mexico Water Resources Research Institute, New Mexico State University, NM. Available online: https:/ / nmwrri.nmsu.edu/tr-390/ (accessed on 4 June 2021).

6. Oil Conservation Division (OCD). OCD Data and Statistics, Oil Conservation Division of the NM Energy, Minerals, and Natural Resources Department, Santa Fe, NM 2020. Available online: http:/ / www.emnrd.state.nm.us/OCD/statistics.html (accessed on 8 June 2021).

7. Wang, Z.; Deshmukh, A.; Du, Y.; Elimelech, M. Minimal and zero liquid discharge with reverse osmosis using low-salt-rejection membranes. Water Res. 2020, 170, 115317. [CrossRef] [PubMed]

8. Cipolletta, G.; Lancioni, N.; Akyol, C.; Eusebi, A.; Fatone, F. Brine treatment technologies towards minimum/zero liquid discharge and resource recovery: State of the art and tech-no-economic assessment. J. Environ. Manag. 2021, 300, 113681. [CrossRef]

9. Panagopolous, A.; Haralambous, K.-J. Miminal liquid discharge (MLD) and zero liquid discharge (ZLD) strategies for wastewater management and resource recovery-Analysis, challenges and prospects. J. Environ. Chem. Eng. 2020, 8, 104418. [CrossRef]

10. AQSim-OLI Electrolyte Solutions. White Paper: Selecting an OLI Thermodynamic Framework for Oil and Gas Production; OLI Systems, Inc.: Parsippany, NJ, USA, 2017. 